
\title{
CIÊNCIA'NATURA
}

\section{Análise da Pluviosidade Mensal e Sazonal nas Bacias Hidrográficas do Ribeirão Santo Antônio e José Manoel no Estado de Goiás}

Analysis of Monthly and Seasonal Rainfall in the Ribeirão Santo Antônio and José Manoel

\author{
River Basins in the State of Goiás
}

Thiago Rocha ${ }^{1}$, Zilda de Fátima Mariano ${ }^{2}$ e Daiane Ferreira Batista ${ }^{3}$

${ }^{1}$ Mestrando, no Programa de Pós-Graduação em Geografia, UFG-Regional Jataí-GO/Brasil thiagolrocha@hotmail.com
${ }^{2}$ Docente, no Programa de Pós-Graduação em Geografia, UFG-Regional Jataí-GO/Brasil zildadefatimamariano@gmail.com

Doutoranda, no Programa de Pós-Graduação em Geografia, UFG-Regional Jataí-GO/Brasil daiane-fb@hotmail.com

\section{Resumo}

Este estudo teve como objetivo compreender a distribuição da precipitação pluvial, nas escalas mensal e sazonal, das bacias hidrográficas do Ribeirão Santo Antônio e José Manuel, localizadas no estado de Goiás. Os dados pluviométricos foram disponibilizados pelo site da Agência Nacional de Águas (ANA), através do sistema hidroweb (2015). Foram baixados dados de chuva em 4 estações próximas à área de estudo, referentes ao periodo de 1974 a 2016. Os dados foram tabulados no programa Excel, extraindo a média mensal da série histórica analisada. Os resultados obtidos pela análise mensal de toda a série histórica mostraram que os meses de janeiro e dezembro foram os que apresentaram as maiores médias pluviométricas, com valores registrados acima dos $250 \mathrm{~mm}$, exceto para a estação de Montividiu/GO, que registrou uma média abaixo de $240 \mathrm{~mm}$ para toda a série. Com isso, conclui-se que os meses com menores valores foram maio, junho, julho e agosto, obtendo média mensal de menos $30 \mathrm{~mm}$ para a série histórica. Para a escala sazonal da área de estudo, o verão caracterizou-se como a estação com maiores índices pluviométricos e o inverno a estação mais seca.

Palavras-chave: Bacia hidrográfica. Precipitação. Série histórica.

\section{Abstract}

This study intented to understand the distribution of the rain on the monthly and seasonal scale at Santo Antônio and José Manuel hydrographic basins which are located in Goiás State. The rainfall datas were extracted of National Water Agency (NWA) through the hidroweb system (2015). Were downloaded datas of rain of four stations next of the study area in a period of 1974 to 2016 . The datas were organized on the software Excel, extracting the average and others statistics information of the historical series. January and December were the months who presented the biggest averages of rain, with values above of $250 \mathrm{~mm}$, except the station of Montividiu where has been registered average less than $240 \mathrm{~mm}$ in all series. The months with the lowest values were May, June, July and August, being the average lowest then $30 \mathrm{~mm}$ for all series. In the seasonal scale the summer was characterized like a station with the highest rainfall index and the winter the driest season. 


\section{Introdução}

Com base na gênese e na dinâmica atmosférica, podem ser desvendadas diversas relações de causa e efeito no conjunto formado pela atmosfera e a superfície. Esse entendimento é fundamental para a compreensão da dinâmica espaço-temporal dos elementos climáticos, principalmente da temperatura, umidade relativa do ar e pluviosidade. Os fatores espaço e tempo (cronológico) são fundamentais na definição dos climas. Para Sant'Anna Neto e Zavattini (2000), é necessário avaliar se as variações do clima são condicionadas por fatores de mudança climática ou se são ciclos periódicos que tendem a se repetir de tempos em tempos, tratando-se apenas de variabilidade do clima.

Os estudos climáticos em bacias hidrográficas estão, cada vez mais, sendo utilizados como referencial para a adoção de práticas de planejamento ou de manejo para o aproveitamento de recursos naturais. Nos dias atuais, um dos temas mais falado e discutido está sendo a questão da água, pois é através da via de circulação que as bacias hidrográficas possibilitam o acesso para o transporte, fonte de abastecimento urbano e industrial e para a geração de energia, sendo, também, caminho para despejo e diluição de efluentes domésticos, industriais e da agricultura. Desse modo, o sistema "bacia hidrográfica" tem se transformado em uma unidade básica para o planejamento e gestão ambiental (BALDO, 2006)

O tema "bacia hidrográfica" é frequentemente utilizado como referencial geográfico em trabalhos acadêmicos e científicos, auxiliando na adoção de práticas corretas de planejamento, manejo e aproveitamento dos recursos naturais. Dada a grande importância da água como via de transporte aquático, geração de energia elétrica, fonte de abastecimento urbano e utilização industrial, a bacia hidrográfica é considerada uma unidade básica para planejamento e gestão ambiental (ROSS E DEL PRETTE, 1998)

Desse modo, entende-se que as bacias hidrográficas são sistemas abertos, que recebem energia por meio de agentes climáticos e perdem energia através do deflúvio, podendo ser descritas em termos de variáveis interdependentes, que oscilam em torno de um padrão. Dessa forma, mesmo quando perturbadas por ações antrópicas, encontram-se em transformação (LIMA E ZAKIA, 2000)

Teodoro et al. (2007) complementam o raciocínio acima, descrevendo que qualquer modificação no recebimento, liberação de energia ou modificação na forma do sistema acarretará mudanças compensatórias, que tendem a minimizar o efeito da modificação e restaurar o estado de equilíbrio dinâmico.

As bacias hidrográficas em questão vêm sofrendo transformações em seu ambiente natural, provenientes das ações antrópicas locais, principalmente na questão do uso da terra. A vegetação é típica do bioma Cerrado, cujas origen nativas, ao longo dos anos, estão sendo substituídas pela principal atividade econômica na região, qual seja, a agropecuária. As áreas mais planas das bacias avaliadas estão passando por transformações em sua ocupação, como a substituição das pastagens por agricultura (soja, milho). Tais atividades são possibilitadas devido aos avanços tecnológicos provindos da agricultura moderna.

Os Ribeirões Santo Antônio e José Manuel são considerados um dos principais contribuintes para o abastecimento da PCH (Pequena Central Hidrelétrica) construída no leito do Rio Caiapó, denominada de PCH Mosquitão. A PCH Mosquitão foi a primeira usina hidrelétrica enquadrada no Programa de Incentivo às Fontes Alternativas de Energia Elétrica (PROINFA), de iniciativa do Governo Federal. Inaugurada em 2006, a usina possui capacidade de geração de $30 \mathrm{MW} / \mathrm{h}$. Com o represamento das águas do rio Caiapó, a área de alagamento é de aproximadamente $4 \mathrm{~km}^{2}$. Esse tipo de ocupação gera alterações no meio ambiente, possibilitando impactos no meio físico natural, tais como a retirada da mata ciliar e alteração da biota aquática e terrestre (LIMA, 2013).
O objetivo deste estudo foi fazer uma análise mensal e sazonal da variabilidade de chuva nas bacias hidrográficas dos Ribeirões Santo Antônio e José Manuel/GO, em escala regional, e detectar os padrões predominantes de distribuição pluvial existentes na região. Para as análises, foram utilizados dados de quatro postos pluviométricos, obtidos junto à ANA (Agência Nacional de Água), entre o período de 1974 a 2016, correspondente a 42 anos de dados.

Portanto, o conhecimento dos padrões predominantes de precipitação pluviométrica em diferentes escalas e sua variabilidade passa a ter uma importância ainda maior no planejamento dos recursos hídricos, no estudo hidrológico, no planejamento urbano e no planejamento agrícola, entre outros (BALDO, 2006).

\section{Materiais e Métodos}

As bacias hidrográficas do Ribeirão Santo Antônio e José Manuel, estão inseridas entre as coordenadas geográficas $16^{\circ} 22^{\prime} 40^{\prime \prime}$ e $16^{\circ} 25^{\prime} 21^{\prime \prime}$ Sul e $51^{\circ} 20^{\prime} 58^{\prime \prime}$ e $51^{\circ} 04^{\prime} 28^{\prime \prime}$ Oeste, na microrregião de Iporá-GO e Aragarças$\mathrm{GO}$, pertencentes à mesorregião Oeste-Goiano e Noroeste Goiano. A área territorial das bacias abrange os municípios de Amorinópolis e Ivolândia, ao sul, Iporá ao norte e Arenópolis, a oeste. As bacias hidrográficas possuem 854,68 Km² de extensão total (Figura 1).

Os postos pluviométricos situam no município de Piranhas, á uma distância da área de estudo de $34 \mathrm{~km}$ aproximadamente, no município de Montes Claros. Ambos foram inseridos na microrregião de Aragarças-GO. Os municípios de Córrego do Ouro está $75 \mathrm{~km}$, na microrregião de Iporá-GO e Montividiu localizado na microrregião de Jataí-GO á uma distancia de $93 \mathrm{~km}$, (Figura1). Os dados de localização de cada posto pluviométrico que foram utilizados neste estudo estão expressos na Tabela 1.

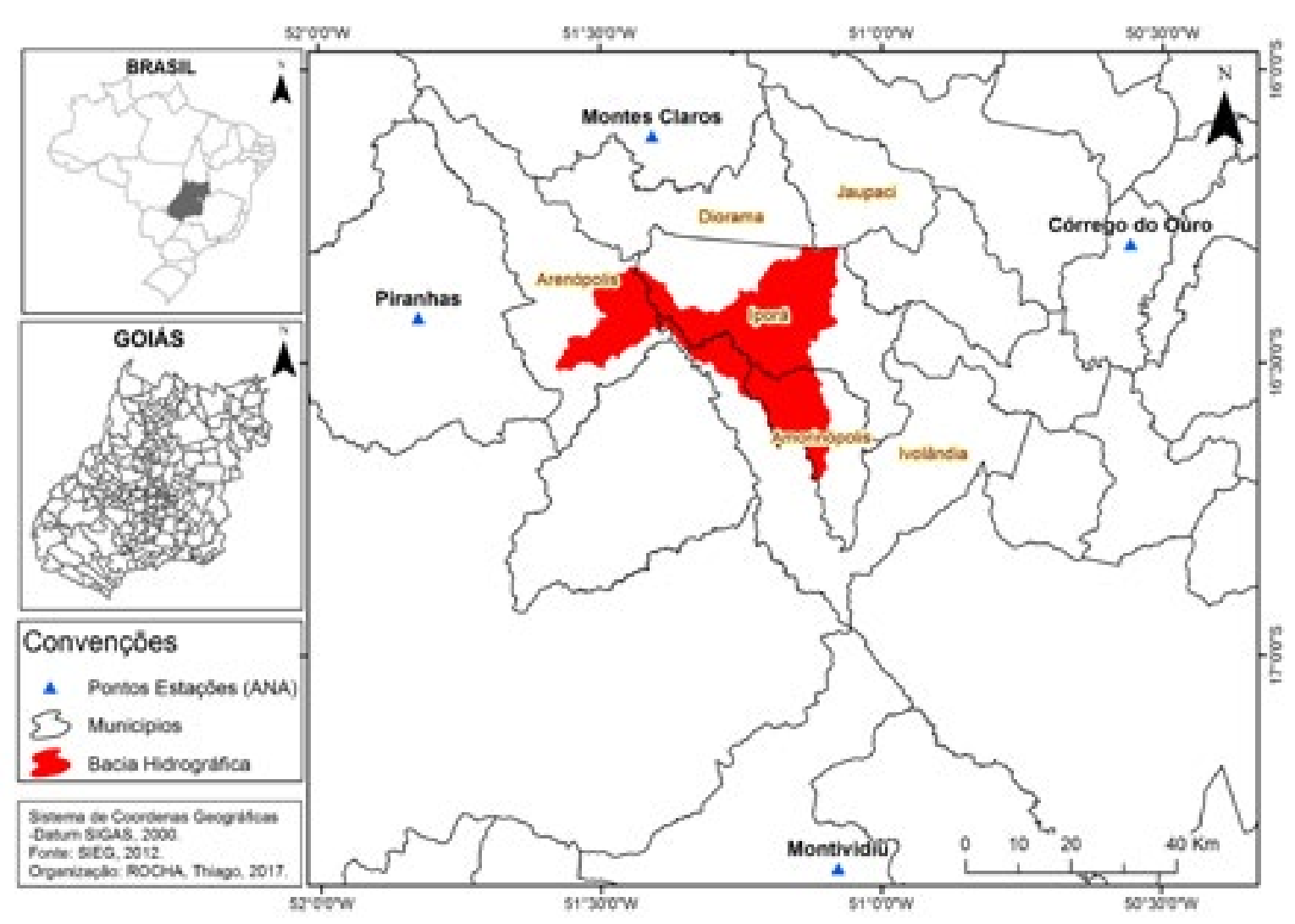

Figura 1 - Mapa de Localizacão da área de estudo e das estaçõs da ANA.
Fonte - SIEG, (2012). Organização: Autores (2017). 
Tabela 1 - Dados de localização das estações pluviométricas da ANA.

\begin{tabular}{|c|c|c|c|c|c|c|c|}
\hline ID & Código da & Localização da estação & Latitude & Longitude & Altitude & Período & Anos \\
\hline & $\begin{array}{l}\text { estação } \\
01610102\end{array}$ & 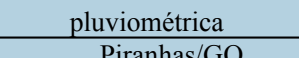 & (S) & (W) & & & \\
\hline 02 & 01651005 & Montes Claros $/ \mathrm{GO}$ & -16 & $\begin{array}{l}-1,1,4067 \\
-51,406 \\
\end{array}$ & 40 & 197 & 42 \\
\hline 03 & 01650001 & Córrego do $\mathrm{O}$ & & & 55. & & 42 \\
\hline 04 & 01751004 & Montividiu/GO & $-17,3647$ & $-51,0767$ & $773 \mathrm{~m}$ & 1974/2016 & 42 \\
\hline
\end{tabular}

Os dados pluviométricos foram disponibilizados pelo site da Agência Nacional de Águas (ANA) através do sistema hidroweb (2015). Foram coletados nas estações mais próximas das bacias em questão, a precipitações pluviais que obtinham a mesma série de dados. Em seguida os dados pluviométricos foram baixados, para geração do banco de dado de cada estação. Posteriormente os dados foram filtrados e analisados para averiguar as falhas mensais e anuais. Com os dados prontos, utilizou-se o software® Excel para geral os gráficos de colunas para a representação dos dados.

\section{Resultados}

Conforme Nimer (1989, p. 394), o clima da região Centro-Oeste brasileira é influenciado pelos fatores físicogeográficos, tais como o posicionamento continental, extensão latitudinal, as características do relevo e a dinâmica da circulação atmosférica.

Outro fator importante que Nimer (1989) destaca é o posicionamento geográfico da região, que se denomina de clima tropical, com pequenas invasões de ar frio de origem polar durante a primavera-verão, acarretando temperaturas elevadas, sobretudo na primavera, ocasião em que o Sol passa pelos paralelos da região, dirigindo-se para o Sul, época em que a estação chuvosa ainda não se iniciou.

Nota-se que Nimer considera que o estado de Goiás recebe atuação de pouca intensidade do que ele chamou de Sistema de Circulação Perturbada, oriundo do deslocamento da Zona de Convergência Intertropical (ZCIT). Essa atuação é pouco intensa e se anula na Latitude entre a divisa dos Estados do Tocantins e Goiás. No que se refere à atuação dos sistemas originados na Amazônia, é apresentado o Sistema de Circulação Perturbada de W, que, segundo o autor, é caracterizado pela Massa Equatorial Continental e as chuvas geradas no seu interior por depressões denominadas linhas de instabilidade, atuantes em toda a área de estudo.

Aos sistemas de Sul, Nimer (1989) denomina-os de Sistema de Circulação Perturbada de S a Frente Polar Atlântica e considera a existência dos avanços Frontais em toda a bacia do Rio Paraná no Oeste Goiano e em porções menores do território onde apresentam elevados gradientes altimétricos.

Nascimento (2011) ressalta que a região Centro-Oeste sofre influência do sistema atmosférico da zona de convergência do atlântico sul (ZCAS), baseado em Nimer (1979), que considera como sendo as linhas de instabilidades tropicais (IT's). Esse sistema atmosférico resulta da intensificação do calor e da umidade provenientes do encontro das massas de ar quente e úmida da Amazônia e do Atlântico Sul.

Marcuzzo et.al (2014) realizaram um estudo aplicando a classificação climática de Köppen e Geiger para o estado de Goiás e Distrito Federal. Para os autores, o estado de Goiás apresenta quatro tipos de clima: Clima tropical úmido ou sub-úmido (Am), Clima tropical com inverno seco (Aw), Clima subtropical de inverno seco (Cwa) e Clima subtropical de altitude com inverno seco e verão ameno $(\mathrm{Cwb})$. Esses tipos de climas têm relação direta com a distribuição pluviométrica do Estado.
Os resultados alcançados nas análises das precipitações médias mensais e sazonais, na série histórica na escala regional, para os quatro postos pluviométricos da ANA, estão apresentados nas Figuras 2A, B, C, D.

Analisando a distribuição da média mensal da precipitação pluvial das bacias em questão, observa-se que os maiores valores em ordem sequencial foram registrados nos postos pluviométricos nos municípios de Piranhas (Figura 2A), Montes Claros de Goiás (Figura 2B), Córrego do Ouro (Figura 2C) e Montividiu (Figura 2D). Nos meses de janeiro, fevereiro, março, novembro e dezembro, foram registrados os maiores valores. Os menores valores foram registrados nos meses de abril, maio, junho, julho, agosto setembro e outubro, em escala regional, para a área de estudo.

O posto pluviométrico de Piranhas (Figura 2A), para o mês de janeiro (considerando-o como mês mais chuvoso), conteve a média mensal do período de 42 anos (1974-2016), com valor de 349,93mm de precipitação. Em dezembro, foi registrada a média de $303,61 \mathrm{~mm}$. Esses meses se destacaram por conterem os maiores registros. Para os meses de fevereiro, março e novembro, obteve-se a média mensal entre 247,68 a $223,59 \mathrm{~mm}$. Julho se destacou como sendo o mês mais seco, registrando $7,42 \mathrm{~mm}$.

Em Montes Claros de Goiás (Figura 2B), os dados pluviométricos do período analisado constaram que o mês de janeiro obteve média mensal de $334,55 \mathrm{~mm}$ e dezembro $325,22 \mathrm{~mm}$, meses estes que são os mais chuvosos. No mês de fevereiro, registrou-se $234,24 \mathrm{~mm}$ e março $257,37 \mathrm{~mm}$ para região das bacias de estudos. Os menores valores foram registrados a partir do mês de abril, com um decréscimo significativo e média mensal de $90,54 \mathrm{~mm}$. No mês de julho foi registrado $5,19 \mathrm{~mm}$, considerado o mês com menor precipitação.

Para o posto pluviométrico de Córrego do Ouro (Figura 2C), as médias mensais que representam o período de análise acompanham a mesma lógica dos demais postos. Os meses de janeiro apresentaram o maio volume de precipitação, com registro de média de $311,88 \mathrm{~mm}$, e dezembro com $287,62 \mathrm{~mm}$. A menor precipitação foi registrada no mês de julho, com 4,24mm, e agosto com 9,37mm.

O posto pluviométrico no município de Montividiu (Figura 2D) obteve a média mensal para os meses mais chuvosos janeiro, março e dezembro, sendo registrada média de $233,63 \mathrm{~mm}$ para o mês de janeiro, $240,92 \mathrm{~mm}$ para dezembro e $288,41 \mathrm{~mm}$ para o mês de março. Os menores valores permaneceram nos meses de junho, com 12,44mm, e $9,66 \mathrm{~mm}$ para o mês de julho.

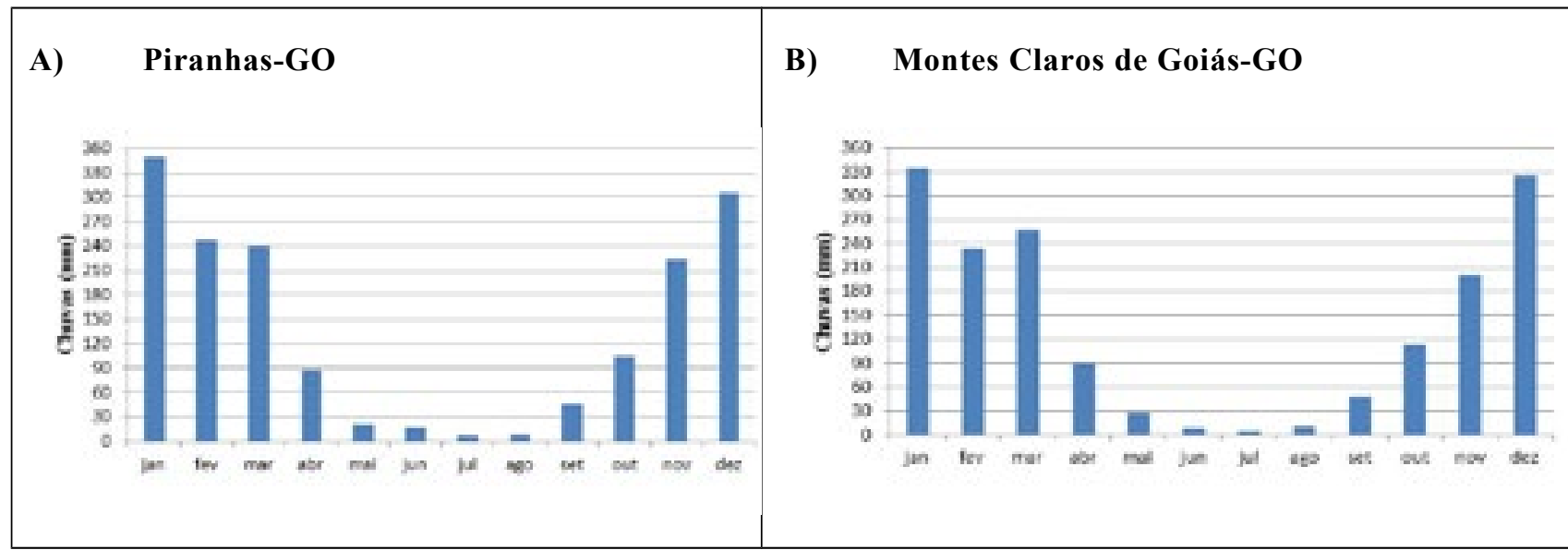




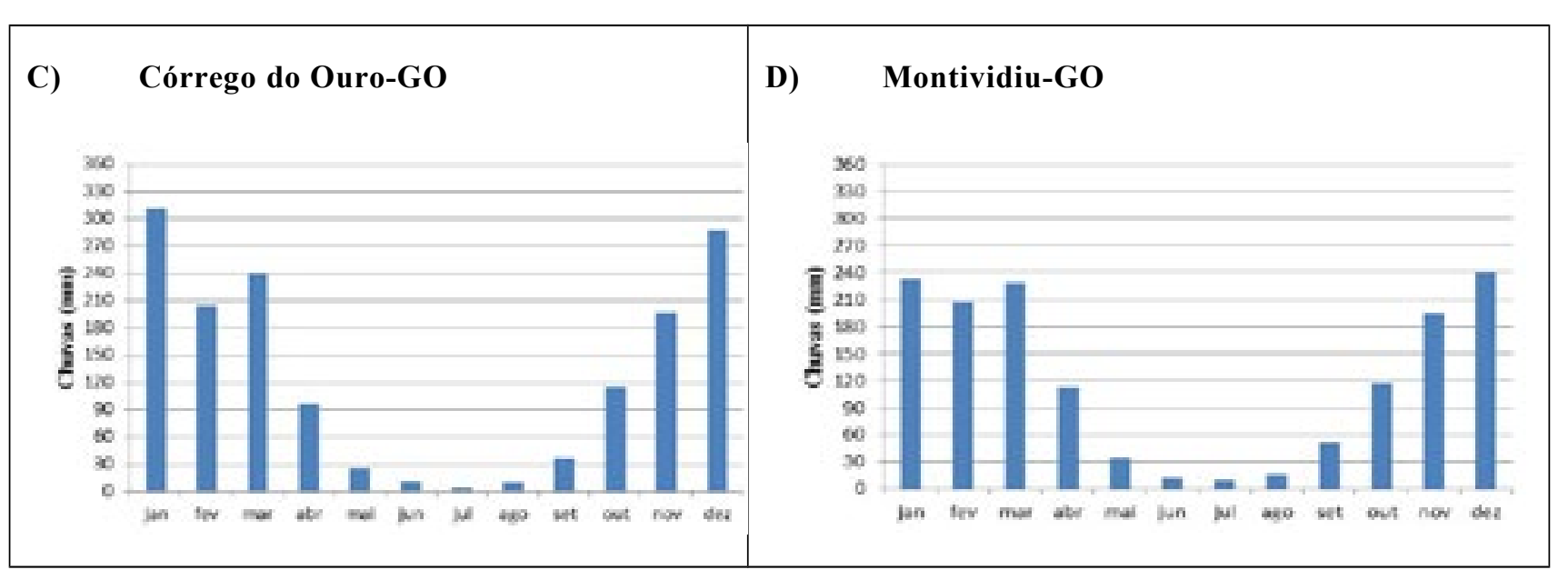

Figura 2 - Dados Pluviométricos da Média Mensal das estações da ANA, no Período de 1974 a 2016. Fonte: ANA, (2017). Organização: Autores, (2017).

Christofoletti (1992) realizou estudos na bacia do Piracicaba-SP, analisando a sazonalidade da precipitação por meio do índice de Walsh e Lawler (1981). A utilização do índice possibilitou a classificação para quantificar os graus de sazonalidade. $\mathrm{O}$ autor constatou que as ocorrências mais comuns na área de estudo recaíram nas classes da distribuição sazonal das chuvas e da distribuição marcadamente sazonal, com pequena estação seca. No estudo da sazonalidade, verificou a existência de baixos valores na variabilidade, considerando tanto a porcentagem da estação chuvosa quanto os índices de sazonalidade. Com esta análise, o autor afirmou que houve homogeneidade em toda a bacia, sem distinguir setores regionais.

Para melhor entender a gênese pluviométrica e sua relação com as variações anuais e sazonais sobre a bacia do rio Corumbataí, em São Paulo, Zavatini e Cano (1993) realizaram uma análise detalhada da sucessão dos estados atmosféricos. Consideraram as intrínsecas relações existentes entre a dinâmica climática e a evolução da paisagem, especialmente em países como o Brasil, em que as flutuações climáticas são, habitualmente, sinônimos de variações do ritmo pluvial.

Para o bioma Cerrado, Nimer (1989) definiu as estações, sendo primavera/verão o período chuvoso e o outono/inverno sendo o período seco. Ao analisar os dados pluviométricos (Figura 3), constatou que, no primeiro semestre, a sazonalidade ocorreu no período da primavera/verão, com índice de pluviosidade crescente, classificando-o como período chuvoso, representando os meses de janeiro, fevereiro, março, abril, outubro, novembro e dezembro.

As sazonalidades do período de estiagem ocorreram entre as estações do outono/inverno, com um decréscimo na pluviosidade. Os meses que representam a estiagem são maio, junho, julho, agosto e setembro. Nesse período, foram registrados, no mês de julho, $6,63 \mathrm{~mm}$, e no mês de setembro foram 46,68mm. Para Nimer (1989), o mês de setembro caracteriza o período de transição entre o semestre seco para o chuvoso (Figura 3).

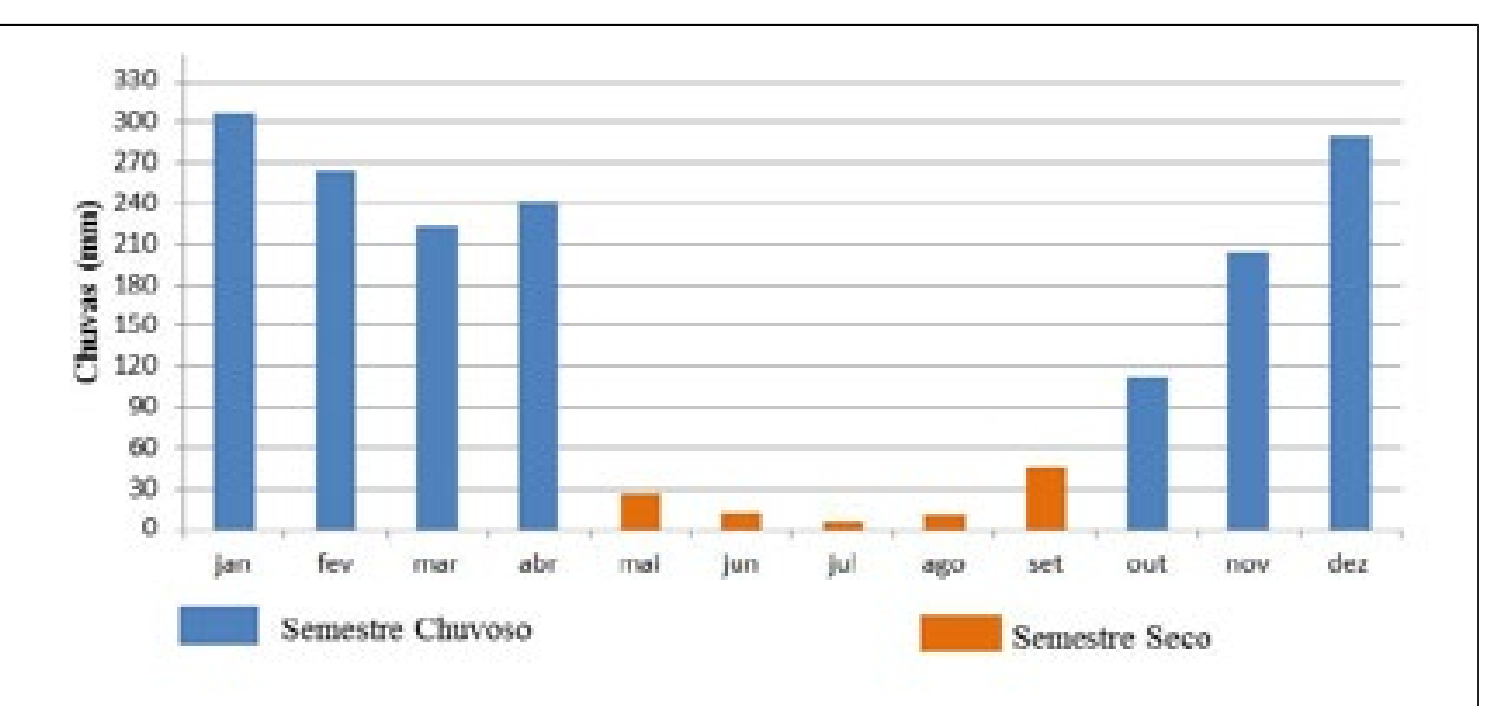

Figura 3 - Histograma dos Totais Médios Mensais de Precipitação Pluviométrica Referente ao Período Histórico de (1974 a 2016). Fonte: ANA, (2017). Organização: Autores, (2017).

\section{Conclusões}

Neste estudo, podemos concluir que, na precipitação média mensal, não se constatam diferenciações significativas entre os postos pluviométricos de Piranhas, Montes Claros e Córrego do Ouro, porque os valores são muito semelhantes entre eles. Essa homogeneidade apresentada se explica por dois fatores: o primeiro refere-se ao fato de a distância entre os postos e o segundo é a variação altimétrica ser pouco significativa. Para o posto pluviométrico de Montividiu, a média mensal apresentou um decréscimo em relação aos demais postos. Vale ressaltar que o posto pluviométrico de Montividiu é o mais distante e com a altitude mais elevada.

Para a sazonalidade, podemos concluir que os dados apresentados mostram que, no bioma do Cerrado, possuímos duas estações bem definidas: primavera/verão sendo o período chuvoso, com valores pluviométricos muito semelhantes e outono/inverno o período seco, com decréscimo da precipitação abaixo de $100 \mathrm{~mm}$.

\section{Agradecimentos}

O presente trabalho foi realizado com o apoio do Programa Nacional de Cooperação Acadêmica da Coordenação de Aperfeiçoamento de Pessoal de Nível Superior - CAPES/Brasil. Edital CAPES 071/2013Processo número 88881.068465/2014-01. Agradecemos aos revisores e colaboradores deste trabalho.

\section{Referências}

ANA - AGÊNCIA NACIONAL DE ÁGUAS. Disponível em: < http:/hidroweb.ana.gov.br/>. Acesso em: 10 abri de 2017.

BALDO, M. C. Variabilidade pluviométrica e a dinâmica atmosférica na bacia hidrográfica do rio Ivaí - PR 2006. 153f. Tese de doutorado (Doutorado em Geografia) Universidade Estadual Paulista, Presidente Prudente - SP 2006. Disponível em: <https://repositorio.unesp.br/bitstream/handle/11449/101431/baldo_mc_dr_prud.pdf 


\section{Referências}

ANA - AGÊNCIA NACIONAL DE ÁGUAS. Disponível em: < http://hidroweb.ana.gov.br/>. Acesso em: 10 abri de 2017.

BALDO, M. C. Variabilidade pluviométrica e a dinâmica atmosférica na bacia hidrográfica do rio Ivaí - PR. 2006. 153f. Tese de doutorado (Doutorado em Geografia) Universidade Estadual Paulista, Presidente Prudente - SP, 2006. Disponível em: <https://repositorio.unesp.br/bitstream/handle/11449/101431/baldo_mc_dr_prud.pdf? sequence $=1>$. Acessado em: 3 jun. 2017.

CHRISTOFOLETTI, A.L.H. Análise da sazonalidade da precipitação na bacia do Piracicaba - SP. Geografia Teorética. Rio Claro, v.17, n.2, p.93-105, 1992.

LIMA, A. M. Relação clima e vegetação na área das bacias das usinas hidrelétricas de Barra dos Coqueiros e Caçu-GO. 2013. Dissertação (Mestrado em Geografia), 89 f. Programa de Pós-graduação em Geografia da UFG, Regional de Jatai-GO. 2013.

LIMA, W.P.; ZAKIA M.J.B. Hidrologia de matas ciliares. In: RODRIGUES; R.R.; LEITÃO. F.; H.F. Matas ciliares: conservação e recuperação. 2 ed. São Paulo: Universidade de São Paulo. 2000, p. 33-43.

MARCUZZO, F. F. N.; CARDOSO, M. R. D.; BARROS, J. R. Classificação climática de Koppen-Geiger para o Estado de Goiás e o Distrito Federal. Revista ACTA geográfica. 2014, v. 8, n. 16, p. 40-55.

NASCIMENTO, D. T. F. Emprego de técnicas de sensoriamento remoto e de geoprocessamento na análise multitemporal do fenômeno de ilhas de calor no município de Goiânia-GO (1986/2010). 2011. 98f. Dissertação de mestrado (Instituto de Estudos Socioambientais) Goiânia, 2011.

NIMER, E. Climatologia da região Centro-Oeste. In: Climatologia do Brasil. 2 ed.. Rio de Janeiro: IBGE, Departamento de recursos naturais e estudos ambientais, 1989, p. 391-404.

ROSS, J. L. S.; DEL PRETTE, M. E. Recursos hídricos e as bacias hidrográficas: âncoras do planejamento e gestão ambiental. Revista do Departamento de Geografia. São Paulo, n.12, p.89-121, 1998.

SAKAMOTO, L. L. S. A chuva na bacia do Alto Paraguai: contribuição ao estudo de aspectos das flutuações interanuais durante o século XX. 2001. 149 f. Tese (Doutorado em Geografia) - Faculdade de Filosofia, Letras e Ciências Humanas, Universidade São Paulo, São Paulo, 2001.

SANT'ANNA NETO, J. A. ; ZAVATINI, J.A. (Org.).Variabilidade e mudanças climáticas: implicações ambientais e socioeconômicas. 21. ed. Maringá: Eduem 2000. p. 95-120.

TEODORO, V. L.; TEIXEIRA, D.; COSTA, D. J. L.; FULlER, B. B. O Conceito de Bacia Hidrográfica e a Importância da Caracterização Morfométrica para o Entendimento da Dinâmica Ambiental Local. Revista UNIARA, 2007, v.20, p. 137-156.Universidade de São Paulo. São Paulo, 2006, n.18, p.89-94.

WALKER, G. T.; BLISS, E. W. Word Weather. V. Mem. Royal Meteorological Society. Inglaterra, n.4, p.53-84, 1932.

ZAVATINI, J. A.; CANO, H. Variações do ritmo pluvial na bacia do rio Corumbataí (SP). Boletim de Geografia Teorética. Rio Claro, v.23, n.45 e 46, p.215-240, 1993. 